\title{
Comparison between clinic and home measurements of blood pressure, total cholesterol, blood sugar to identify 10 -year atherosclerotic cardiovascular disease risk score
}

\author{
Putri Ani Sunjaya*, Agatha Nensida Venary, \\ Ruth Estika Ave Haryono, Rita Suhadi \\ Faculty of Pharmacy, Sanata Dharma University \\ Kampus III, Paingan, Maguwoharjo, Depok, Sleman, Yogyakarta, Indonesia
}

Accepted: 06-04-2021

\begin{abstract}
The clinical guideline recommends home monitoring for hypertension, diabetes, and hyperlipidemia maintenance therapy. The study aimed to compare the 10-year atherosclerotic cardiovascular disease (ASCVD) risk calculated using systolic blood pressure, fasting totalcholesterol, and fasting blood sugar measured at the clinic and home. This analytical cross-sectional study was done in population from villages in Sleman District, Yogyakarta. The subjects were selected purposively with the criteria of 40-79 years old and signing the informed consent. The home-measured systolic blood pressure was monitored with a digital sphygmomanometer and peripheral finger-stick methods for cholesterol and blood sugar. On the same occasion, the clinic measurements were monitored with a mercury sphygmomanometer for systolic blood pressure, and with venous plasma analyzed in the laboratory for cholesterol and blood glucose. Measurements between methods were compared with paired T-tests. The subjects $(\mathrm{n}=171)$ had a mean age of $52.6(8.1)$ years; $21.6 \%$ were male. The systolic blood pressure, total cholesterol, and blood glucose from clinic and home measurement were $130.0(21.1) \mathrm{mmHg}$ and $137.6(22.4) \mathrm{mmHg}(\mathrm{p}<0.001) ; 202.8$ (32.8) $\mathrm{mg} / \mathrm{dl}$ and $205.2(44.8) \mathrm{mg} / \mathrm{dl}(\mathrm{p}=0.44)$; and $98.5(42.9) \mathrm{mg} / \mathrm{dl}$ and $91.9(34.6) \mathrm{mg} / \mathrm{dl}(\mathrm{p}<0.001)$ respectively. The average ASCVD risks of the clinic and home measurements were $6.4(6.2) \%$ and $7.1(6.9) \%$ $(\mathrm{p}<0.001)$; however, both methods had the same ASCVD risk category at borderline risk $(5-<7.5 \%)$. Conclusion: The ASCVD risk scores calculated using clinic and home measurements were statistically different.
\end{abstract}

Keywords: Atherosclerotic Cardiovascular Disease (ASCVD), Blood Pressure, Blood Sugar; Totalcholesterol, Home Measurement

*Corresponding author:

Putri Ani Sunjaya

Faculty of Pharmacy, Sanata Dharma University

Kampus III, Paingan, Maguwoharjo, Depok, Sleman, Yogyakarta, Indonesia

Email: putrianisunjaya @gmail.com 


\section{INTRODUCTION}

Cardiovascular disease is the highest prevalence of non-communicable disease in Indonesia (Pariona, 2017). In 2015, the global morbidity rate and mortality rate of cardiovascular disease were estimated at 422.7 million (95\% uncertainty interval: 415.5 to 427.9 million) and 17.9 million (95\% uncertainty interval of 17.6 to 18.3 million) respectively (Roth et al., 2017). Atherosclerosis is responsible for cardiovascular diseases, namely coronary arterial disease, ischemic stroke, and peripheral arterial disease, recently known as Atherosclerotic Cardiovascular Diseases (ASCVD) (Grundy et al., 2019; Stone et al., 2015). Hypertension, hyperlipidemia, diabetes, and bad healthy lifestyles, including smoking, stressful life, sedentary life, and poor diet, are recognized as cardiovascular risk factors. These factors induce the development of atherosclerosis. Exposure to the risk factors accelerates atherosclerosis and the complex plaque-forming process. Atherosclerosis constricts blood vessels, blocks the blood flow, and produces serious health problems in some vital organs, e.g., heart, brain, and kidney (Douglas and Channon, 2014).

The home measurement of blood pressure, total cholesterol, and fasting blood glucose is monitored by patients or their family members without health professional assistance. In contrast, healthcare professionals generally do the clinic measurement. A rural community is relatively far from health professionals and facilities. A study showed that capillary blood sugar levels could be used to replace venous blood sugar (Midilli et al., 2019). Maintenance of blood pressure, total cholesterol, and blood sugar target will reduce the atherosclerotic cardiovascular disease (ASCVD) risk, diabetes mellitus type 2, and stroke (Riddle et al., 2018; Stone et al., 2015). The ASCVD risk can be predicted using the ASCVD calculation. The Pooled Cohort Equations (PCE) system is the newest version in the 10-year ASCVD risk prediction and presented in percentage (Lloyd-Jones et al., 2019). Intervention for prevention and treatment for ASCVD can be provided for the intermediate and high-risk subjects as early as possible (Stone et al., 2015).

Numerous studies had compared the clinic and home measurements with inconsistent results. However, no similar study in ASCVD risk comparison using clinic and home measurement values has been found from any journal database. This study was aimed to compare the ASCVD risk score calculated using the PCE method obtained from the clinic and home measurements of blood pressure, total cholesterol, and blood sugar among the rural community subjects. This research helps both subjects, doctors, and pharmacists, especially in rural areas, choose the best measurement method of an ASCVD risk score to get rapid intervention or education for subjects with an intermediate and high risk of ASCVD. Along with that, screening and monitoring the risk factor of ASCVD could be done earlier by pharmacists to reduce cardiovascular disease morbidity and mortality rates.

\section{MATERIALS AND METHOD \\ Materials}

Case Report Form (CRF) was used to document the measurement and the subject's profiles, including the ASCVD parameters, namely age, sex, race, smoking status, diabetes status, and hypertension therapy status. The clinical SBP measurement was obtained from a mercury sphygmomanometer, while home SBP was measured using a digital sphygmomanometer (OMRON®). Home FBS was obtained using the instruments for the peripheral finger-stick blood sugar. Meanwhile, the home total cholesterol was measured using 1 set of Accu-check ${ }^{\circledR}$ and two (2) sets of Easytouch ${ }^{\circledR}$.

\section{Methods}

The study was conducted with the observational method and done with the analytical crosssectional design. Data were collected among the subjects in Sleman District, Yogyakarta, Indonesia, under medical doctors' supervision. The research was conducted from June to August 2017. The subject's profiles were collected with written CRF. 
The subject selection was made with a purposive sampling method from the community in Sleman District. The subject's criteria were adult, fasting for 8-10 hours before blood sampling, and agreed to participate in the study by signing informed consent. Whereas the excluded subjects were ones with a history of overt cardiovascular disease, pregnancy, or exceeded the permitted values of age, SBP, total cholesterol, or HDL-cholesterol. The minimum samples of subjects for paired T-test analysis were calculated with $\alpha(5 \%), \beta(20 \%)$, mean difference for ASCVD between method $(\delta)$ at 0.5 , and standard deviation $(\sigma)$ at 1.5 ; resulted in 73 subjects per group (Dupont and Plummer, 1998). While minimum sample for moderately strong correlation ( $r>0.6$; power $80 \%)$ was 17 subjects per group (Chan, 2005).

Of the 205 subjects participated in the study, 34 subjects were excluded because suffered from ASCVD namely stroke $(n=2)$, coronary arterial disease $(n=2)$, and heart failure plus thyroid disease $(\mathrm{n}=1)$; and the data can not be calculated with ASCVD formula due to $<40$ years old $(\mathrm{n}=13)$, high SBP at $>200 \mathrm{mmHg}(\mathrm{n}=4)$, high total cholesterol at $>320 \mathrm{mg} / \mathrm{dl} \quad(\mathrm{n}=6)$, low total cholesterol at $<130 \mathrm{mg} / \mathrm{dl}(\mathrm{n}=4)$, and low HDL-cholesterol at $<20 \mathrm{mg} / \mathrm{dl}(\mathrm{n}=2)$.

Measurements of both blood pressure methods, home measurement of total cholesterol and FBS, were performed at the study sites. On the same occasion with peripheral blood sampling, the venous plasma samples for FBS, total-cholesterol, HDL-cholesterol levels for clinic measurement were conducted in the study sites by the laboratory technician and transported to $\mathrm{P}$ (anonymous) Laboratory ${ }^{\circledR}$ for the blood chemical assay. The clinic FBS was determined with the plasma hexokinase method, whereas the total-cholesterol concentration was determined with the CHOD-PAP method.

Before conducting the study, the measurement instruments used in this study, including the $\mathrm{CRF}$, were validated to ensure a valid and reliable measurement. The CRF was tested on some volunteers to assess the subject's understanding of the content. In addition, the validation of sphygmomanometer had been validated by the external calibrator.

Several field data collectors did the SBP of clinic measurement, and the SBP measurements were likely to have different perceptions among observers. Therefore, the reliability tests between observers were necessary done in three subjects with triple replication for each observer. After that, the data were analyzed using paired T-tests. The paired T-tests had $p$-values at $>0.05$, which indicated no difference of perception between observers.

The reliability tests for the instruments of total cholesterol and fasting blood glucose were done in 3 subjects with triple replication. The coefficient variance (CV) value within the instrument was then calculated. The mean CV of the reliability test for Accu-check ${ }^{\circledR}$ was $2.9(3.2 \%)$, while the mean $\mathrm{CV}$ for two sets of EasyTouch ${ }^{\circledR}$ was $5.6(1.9 \%)$ and 4.5 (7.1\%). The standard CV value within the instrument should be below $5-10 \%$ based on the standard CV criteria, which states that instruments with fewer than five replications should be valid for imprecision levels at $<5-10 \%$ CV (Davis et al., 2013).

The 10-year prediction of ASCVD risk score was measured using the online calculator of ASCVD Risk Estimator. The ASCVD risk was categorized as a low risk at $<5 \%$, borderline risk at $5 \%-<7.5 \%$, intermediate risk at $7.5 \%-<20 \%$, and high risk at $\geq 20 \%$. The calculator is applicable only for the following variables, namely age of $40-79$ years, SBP at $90-200 \mathrm{mmHg}$, DBP at $60-130 \mathrm{mmHg}$, total cholesterol at $130-320 \mathrm{mg} / \mathrm{dl}$, HDL-cholesterol at $20-100 \mathrm{mg} / \mathrm{dl}$, and LDL-cholesterol at $30-$ $300 \mathrm{mg} / \mathrm{dl}$ (Lloyd-Jones et al., 2019). In this study, the discussion focused on the variables of SBP, total cholesterol, and HDL-cholesterol.

The validity tests for home methods of SBP, total-cholesterol, FBS, and 10-year ASCVD risk score were conducted to compare with those values from clinic methods and analyzed with paired numerical comparative tests, namely paired T-tests. Prior to the T-test, the normality of data distribution was done using the Kolmogorov-Smirnov Test. The clinic and home measurements for SBP, total-cholesterol, FBS, and ASCVD risk showed that the data distribution was not normal (normality test result with $\mathrm{p}$-value $<0.001$ ). According to the central limit theorem, the sample size with 30 and more subjects can be assumed to be normal distribution population regardless of the 
distribution result (Kwak and Kim, 2017). Based on the central limit theorem, the analysis for ASCVD risk was done with paired T-test.

The agreement between the clinic and home measurements on categorizing diabetic subjects was carried out with the Kappa test, and the sensitivity and specificity levels were analyzed with a home method. The sensitivity and specificity were obtained with one minus false-negative rate (1FNR) and one minus false-positive rate (1-FPR), respectively. All hypotheses were analyzed under 95\% significant statistics. The statistical data were analyzed by an external statistician in Clinical Epidemiology \& Biostatistics Unit Study Center (CEBU) Universitas Gadjah Mada using the IBM SPSS Statistics 22 program.

\section{Ethics statement}

This study was done with the ethical clearance No. 436/C.16/FK/2017 and 437/C.16/FK/2017 issued by Medical Research and Medical Ethics Committee of Faculty of Medicine, Universitas Kristen Duta Wacana, Indonesia. This study was done with a descriptive method. The subjects were described with the study procedure and requested to sign informed consent before the study was conducted. The possible harm was infection and bruise at the blood-sampling site. This adverse effect was minimized with the aseptic sampling technique by the laboratory staff. In this study and its publication, all subjects were treated as anonymous.

\section{RESULTS AND DISCUSSION}

This study aimed to compare the 10-year ASCVD risk scores using the clinic and home measurements of SBP, FBS, and fasting total-cholesterol measurements. The substitution from the clinic measurement to the home measurement for ASCVD risk calculation has the purpose of early risk detection, particularly for the subjects from a rural community or far from a health facility. The portable digital instruments of SBP, total cholesterol, and FBG were generally available at home in the community. Whereas the SBP, total cholesterol, and FBG are the ASCVD risk components of the PCE method. Parameters from clinical measurements are the golden standard to diagnose ASCVD risk. However, home measurements are more practical for subjects in monitoring the ASCVD parameters. Subjects who were particularly far from health access will obtain advantages if the ASCVD risk can be monitored using home measurement. The clinician has used the ASCVD risk to initiate statin therapy for the high-risk subjects since 2013 (Stone et al., 2015).

\section{Subjects' characteristics}

The ASCVD parameters other than SBP, total cholesterol, and blood sugar in overall subjects $(n=171)$ were described as follow: few male subjects (21.6\%), high prevalence of smokers $(52.0 \%)$, hyperglycemia subjects (9.9\%), hypertension therapy receivers (19.9\%), and non-white/black race subjects (100\%); mean age of 52.6 (8.1) years old; with relatively high total-cholesterol and/or LDLcholesterol; with relatively normal average fasting blood glucose; and with average SBP/DBP higher than the normal cut-off. (Table 1). 
Table 1. Subjects' characteristics of ASCVD risk component

\begin{tabular}{cc}
\hline Subject's Characteristics & Results \\
\hline Male $\mathrm{n}(\%)$ & $37(21.6)$ \\
Smoking status $\mathrm{s}^{\mathrm{a}} \mathrm{n}(\%)$ & $89(52.0)$ \\
Hyperglycemia $\mathrm{n}(\%)$ & $17(9.9)$ \\
Therapy of hypertension status $\mathrm{n}$ & $34(19.9)$ \\
(\%) & $52.6(8.1) \mathrm{y} . \mathrm{o}$. \\
Age: mean (SD) & $202.8(32.8) \mathrm{mg} / \mathrm{dl}$ \\
Total-Cholesterol: mean (SD) & $129.8(29.5) \mathrm{mg} / \mathrm{dl}$ \\
LDL-C: mean (SD) & $50.9(12.7) \mathrm{mg} / \mathrm{dl}$ \\
HDL-C: mean (SD) & $98.5(42.9) \mathrm{mg} / \mathrm{dl}$ \\
FBG: mean (SD) & $130.0(21.1) \mathrm{mmHg}$ \\
SBP: mean (SD) & $83.8(10.4) \mathrm{mmHg}$ \\
DBP: mean (SD)
\end{tabular}

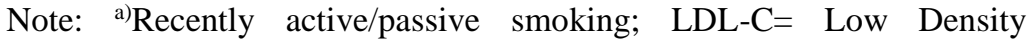
Lipoprotein-Cholesterol; HDL-C=High Density Lipoprotein-Cholesterol; $\mathrm{FBG}=$ Fasting Blood Glucose; $\mathrm{SBP}=$ systolic blood pressure; DBP diastolic blood pressure; $\mathrm{SD}=$ Standard Deviation; non-white/black subjects $=100 \%$

\section{Clinic versus home blood pressure, total-cholesterol, and fasting blood glucose}

The SBP's sub-groups were categorized based on ACC/AHA guidelines. The home measurement results for SBPs were significantly higher than the clinic SBP $(p<0.001)$ in the total subjects and the SBP sub-groups. Similar results of higher home DBP were found in total subjects and in sub-groups $<90 \mathrm{mmHg}$ with clinic measurement $(p<0.05)$, but in the subjects with $\geq 90 \mathrm{mmHg}$ DBP had insignificant higher home DBP than clinic DBP. This study's finding had the opposite results from the previous studies showed that the mean SBP from clinic measurement was higher than the home measurement (Myers et al., 2008; Nargesi et al., 2014). Home (digital) sphygmomanometers often use oscillometry techniques, similar to auscultation used in clinical (mercury) sphygmomanometers. Auscultation technique needs a professional's skill owned by healthcare personnel (Pickering et al., 2005). Therefore, digital sphygmomanometer usage is more patient-friendly and more frequently used in self-monitoring of SBP/DBP at home by the patients.

Some factors can affect BP measurements, causing differences between home and clinic BP monitoring results. According to American Diagnostic Corporation (2008), the first factor which possibly affects the result is the sitting duration (American Diagnostic Corporation, 2008). The longer the subject sits waiting for BP to be measured, the more probable they are relaxed, and their BPs are more stabilized. As recommended by American Heart Association (AHA) and the British Hypertension Society (BHS), patients need to be seated without talking for more or less five minutes before the measurement. Nevertheless, apart from a thoughtful recommendation, other factors that can interfere with the measurements depend on patients' conditions, such as their stress level, physiology, and activities done prior to the measurement. In fact, the first measurement will likely result in relatively higher than the following measurements despite the resting interval. Another factor to consider was the difference in blood pressure cuffs size from two different sphygmomanometers. The cuff that is too small will overestimate the BP. Based on a study that focuses on cuff application, too small cuff justified $84 \%$ of cuff sizing errors, which is dramatically more significant than the errors due to the too large cuff size.

Furthermore, the difference between using home and clinic measurements identifies the patients with white-coat hypertension or masked hypertension. Patients with white-coat hypertension experience high BP only in the clinic measurement, whereas individuals with masked hypertension 
have elevated BP only in the home measurement (Unger et al., 2020). White-coat hypertension and masked hypertension are caused by a particular environment that results in inaccurate blood pressure readings. White-coat hypertension indicates that the patients result in relatively high blood pressure when doctors or clinicians check it at doctor's practices but not at home. It is defined with clinical systolic $\mathrm{BP} \geq 140 \mathrm{mmHg}$ and/or diastolic $\mathrm{BP} \geq 90 \mathrm{mmHg}$ measurement and showed home systolic $\mathrm{BP}<135 \mathrm{mmHg}$ and diastolic $\mathrm{BP}<85 \mathrm{mmHg}$. On the other hand, masked hypertension implies contrasting situations where the patients encounter high blood pressure at different environments than doctor's practices, such as at home. It is defined with home systolic $\mathrm{BP} \geq 135 \mathrm{mmHg}$ and/or diastolic $\mathrm{BP} \geq 85 \mathrm{mmHg}$, whereas it showed clinical systolic $\mathrm{BP}<140 \mathrm{mmHg}$ and diastolic $\mathrm{BP}<90 \mathrm{mmHg}$ measurement (Stergiou et al., 2014). Commonly, these conditions exist among untreated or treated subjects for hypertension. It is also shown that about $10 \%-30 \%$ of individuals who come to the clinics due to high blood pressure have white coat hypertension, and $10 \%-15 \%$ possess masked hypertension (Unger et al., 2020).

The clinic and the home measurements of total cholesterol in the overall subjects were 202.8 (32.8) $\mathrm{mg} / \mathrm{dl}$ and 205.2(44.8) $\mathrm{mg} / \mathrm{dl}(p=0.44)$. The clinic and home total cholesterol measurements had inconsistent differences with higher and lower values than home measurements. Though the measurements were not significantly different, the home measurement was not recommended for substitution because it had the lowest correlation coefficient among other variables. This study's results were different from the previous study, which stated that total cholesterol was insignificantly higher than clinic measurement (Sblendorio et al., 2008). The clinic and home measurements use different samples in measurements; the cholesterol distribution in the lymphatic fluid or interstitial on the peripheral vascular system was $10 \%$ of the plasma's cholesterol (Greenland et al., 1990). Given the above description, the cholesterol level in peripheral vascular used in the home measurement should be lower than the clinic method.

The clinic-measured and home-measured FBS in total subjects were $98.5(42.9) \mathrm{mg} / \mathrm{dl}$ and 91.9 (34.6) $\mathrm{mg} / \mathrm{dl}(p<0.001)$. Significantly lower home-measured FBGs were found in FBG sub-group of $<100 \mathrm{mg} / \mathrm{dl}, \geq 126 \mathrm{mg} / \mathrm{dl}$ sub-groups, and in total subjects; except for $100-125 \mathrm{mg} / \mathrm{dl}$ with an insignificantly different value. The result was different from the previous studies, in which the blood sugar level obtained from the clinic was lower than the home measurement (Boyd et al., 2005; Midilli et al., 2019). A study with a higher value of capillary whole blood sugar level done using the 2-hour OGTT had an increase of $0.8 \mathrm{mmol} / \mathrm{L}$ sugar level compared to the method measured using venous laboratory plasma sugar (Blaurock et al., 2018). The clinic measurement for blood sugar used the blood plasma, whereas the home measurement used the whole blood. Plasma used in the clinic measurement has higher water composition; thereby, it has higher blood sugar levels (Patel and Patel, 2015; Rajaratnam and Pathmanathan, 2012). The Kappa test result with the Kappa coefficient at 0.959, $p<0.001$, showed a very good agreement in determining diabetes status between the clinic and home methods. Both clinic and home methods measurements showed no difference in diabetes prevalence due to similar categorizations of diabetic or non-diabetic subjects. The home-measured FBG in this study also had high sensitivity and specificity rate.

The correlation coefficient (r) interpretation (Chan, 2005) of the clinic and home measurements from the highest to the lowest correlations were: FBG (r: 0.959, $p<0.001$ categorized as very strong correlation), SBP ( $\mathrm{r}$ : 0.898, $\mathrm{p}<0.001$, very strong), DBP (r:0.752, $\mathrm{p}<0.001$, moderately strong correlation), and total-cholesterol ( $\mathrm{r}: 0.499, \mathrm{p}<0.001$, fair correlation). The clinic and home measurements have a strong agreement in the determination of diabetes. The home measurement also had high sensitivity and specificity rate in the determination of diabetes as compared with the clinic measurement. (Table 2) 
Table 2. Comparison systolic blood pressure (SBP), diastolic blood pressure, total-cholesterol, and fasting blood glucose between clinic versus home measurement

\begin{tabular}{lccc}
\hline \multicolumn{1}{c}{ Category } & $\begin{array}{c}\text { Clinic } \\
\text { Mean }(\text { SD) }\end{array}$ & $\begin{array}{c}\text { Home } \\
\text { Mean }(\text { SD) }\end{array}$ & p-value \\
\hline & Systolic Blood Pressure or SBP $(\mathbf{m m H g})$ & \\
\hline$<120(\mathrm{n}=45)$ & $106.2(5.6)$ & $116.9(11.2)$ & $<0.001$ \\
$120-129(\mathrm{n}=37)$ & $120.1(0.8)$ & $125.8(8.8)$ & $<0.001$ \\
$130-139(\mathrm{n}=28)$ & $130.2(0.9)$ & $137.1(8.3)$ & $<0.001$ \\
$\geq 140(\mathrm{n}=61)$ & $153.4(14.1)$ & $160.4(17.8)$ & $<0.001$ \\
Total subjects & $130.0(21.1)$ & $137.6(22.4)$ & $<0.001$
\end{tabular}

In total subjects correlation (r) SBP: 0.898; p-value: $<0.001$

Note: SBPs were based on ACC/AHA guidelines (Whelton et al., 2017).

\begin{tabular}{lccc}
\hline \multicolumn{4}{c}{ Diastolic Blood Pressure or DBP $(\mathbf{m m H g})$} \\
\hline$<80(\mathrm{n}=30)$ & $68.6(4.3)$ & $73.3 .(7.8)$ & 0.003 \\
$80-89(\mathrm{n}=72)$ & $80.1(0.6)$ & $82.3(7.7)$ & 0.01 \\
$\geq 90(\mathrm{n}=69)$ & $94.4(5.7)$ & $95.5(10.4)$ & 0.25 \\
Total subjects & $83.8(10.4)$ & $86.1(12.2)$ & $<0.001$
\end{tabular}

In total subjects correlation (r) DBP: 0.752; p-value: $<0.001$

\begin{tabular}{lcrr}
\hline \multicolumn{4}{c}{ Total-cholesterol or T-C $(\mathbf{m g} / \mathbf{d l})$} \\
\hline$<200(\mathrm{n}=85)$ & $176.7(16.3)$ & $185.6(32.0)$ & 0.01 \\
$200-<240(\mathrm{n}=61)$ & $216.6(12.7)$ & $217.5(44.3)$ & 0.87 \\
$\geq 240(\mathrm{n}=25)$ & $257.8(15.5)$ & $241.7(51.3)$ & 0.13 \\
Total subjects & $202.8(32.8)$ & $205.2(44.8)$ & 0.44 \\
& In total subjects correlation (r) T-C: $0.499 ; \mathrm{p}$-value: $<0.001$
\end{tabular}

\begin{tabular}{lccc}
\hline \multicolumn{4}{c}{ Fasting Blood Glucose or FBG (mg/dl) } \\
\hline$<100(\mathrm{n}=138)$ & $83.8(7.3)$ & $80.2(8.9)$ & $<0.001$ \\
$100-125(\mathrm{n}=16)$ & $106.4(5.5)$ & $100.8(17.6)$ & 0.19 \\
$\geq 126(\mathrm{n}=17)$ & $210.6(61.2)$ & $179.1(48.9)$ & $<0.001$ \\
Total Subjects & $98.5(42.9)$ & $91.9(34.6)$ & $<0.001$
\end{tabular}

In total subjects correlation (r) FBG: 0.959; p-value: $<0.001$

Determination of DM with home measurement: sensitivity $=1$-FNR $=0.941 ;$ specificity $=1-\mathrm{FPR}=0.994 ; \mathrm{FNR}=$ false negative rate; and $\mathrm{FPR}=$ false positive rate.

Kappa coefficient for DM threshold $=0.935 ; \mathrm{p}<0.001$ very strong agreement between clinic and home measurement (Gisev et al., 2013)

\footnotetext{
Note:

Clinic-measurements consisted of blood pressure with a mercury sphygmomanometer, total cholesterol, and Fasting Blood Glucose using the vena sample and analyzed in a laboratory. Home measurement consisted of blood pressure with a digital sphygmomanometer, total-cholesterol, and Fasting Blood Glucose using finger-stick samples and measured with portable home instruments.
}

\section{ASCVD risk score from clinic and home measurement}

The mean ASCVD risk score from clinic measurement for all instruments in total subjects was $6.4(6.2) \%$, whereas the mean score from home measurement was $7.1(6.9) \%(p=0.001)$. Substitution of a single parameter of ASCVD risk with home-measured SBP while the remaining parameters with clinic measurements have the result of the ASCVD score at $7.1(6.9) \%$; significantly different from the standard clinic measurement $(p<0.001)$. Similar substitution for single measurement home-measured FBS and total cholesterol results were $6.4(6.2) \%(p: 0.85)$ and $6.4(6.2) \%(p: 0.56)$; not significantly different from standard measurement. However, the ASCVD measurements from four observed 
methods were classified in the same category: borderline risk in the range of 5\%-7.5\%. In ASCVD subgroup analysis, the home measurement had significantly different ASCVD risk from the standard clinic measurement except for high-risk subjects. Nevertheless, the high-risk subgroup had only 7 subjects and needed further confirmation. The results shown above indicate statistical differences but were not reflected on the clinical ASCVD risk stratification. Furthermore, in ASCVD subgroup analysis, the substitution of the single parameter of SBP but not total-cholesterol or FBG had resulted in significantly different ASCVD risk scores from the clinic measurement (Table 3).

Mean ASCVD risk score calculated using clinic and home measurement were significantly different ( $p=0.001$ ). The ASCVD risk derived from home-measured SBP, total cholesterol, and blood sugar measurement cannot represent the standard measurement in a normal setting for ASCVD risk determination. The home-measured SBP was significantly different when implemented in the ASCVD risk score calculation, whereas the results were not significantly different with home-measured total cholesterol and FBG. The home-measured FBG substitution was likely the best among the two other variables. In the total subjects, the mean home and clinic measurement of SBP, total cholesterol, and FBG had the same risk category. In this study, the home measurement can be recommended as the secondary alternative for monitoring and evaluation therapy temporarily when the clinic measurement was not available. When the home measurement was used to temporarily substitute the clinic measurement for early detection of the component of ASCVD risk, the clinic measurement should reconfirm the result at the soonest. A study of peripheral or finger-stick method clinical use in the measurement of subject's cholesterol level showed that the method is appropriate to detect subject's hyperlipidemia and meet the criteria for cardiovascular disease prevention (Parikh et al., 2009).

The mean ASCVD risk using clinic measurement was 6.6 (5.9)\%, which indicated that the subjects were at borderline cardiovascular risk $(5 \%-<7.5 \%)$. The ASCVD risk was similar to previous research done in the villages in Sleman District, Yogyakarta. The previous study showed the subjects had moderate CVD risk calculated using Framingham Score at 11.4(8.9)\% (Suhadi et al., 2017).

Some limitations technically occurred in this study; home method instrument for HDLcholesterol had not been available yet in the community. The HDL-cholesterol level as a component in the calculation of ASCVD risk was obtained from clinic measurement. The number of subjects for the analysis in sub-groups was insufficient and different in each sub-group, though the total subjects met the study's minimum sample. Due to the limitation mentioned above, the results were not likely to be implemented in other settings or when the standard measurement facilities were available. Further study is needed to compare clinic-measured and home-measured SBP, total cholesterol, blood sugar levels in calculating ASCVD risk and confirm this study. 
Table 3. ASCVD risk comparison between clinic and home measurement and a single systolic blood pressure, total-cholesterol, and fasting blood glucose home parameter substitution

\begin{tabular}{|c|c|c|c|c|c|c|c|c|c|}
\hline \multirow[t]{2}{*}{ Risk Category } & \multirow{2}{*}{$\begin{array}{c}\text { Standard } \\
\text { Measurement } \\
\text { (Clinic SBP, } \\
\text { TC,\& FBG)) }\end{array}$} & \multicolumn{2}{|c|}{$\begin{array}{c}\text { Home (SBP, TC, FBG) } \\
\text { Measurement }\end{array}$} & \multicolumn{2}{|c|}{$\begin{array}{c}\text { Home SBP, Clinic } \\
\text { TC\&FBG Measurement }\end{array}$} & \multicolumn{2}{|c|}{$\begin{array}{c}\text { Clinic SBP, Home TC, } \\
\text { Clinic FBG Measurement }\end{array}$} & \multicolumn{2}{|c|}{$\begin{array}{c}\text { Clinic SBP \& TC, Home } \\
\text { FBG Measurement }\end{array}$} \\
\hline & & Mean (SD) & $\begin{array}{c}\text { Versus } \\
\text { standard p- } \\
\text { value }\end{array}$ & Mean (SD) & $\begin{array}{c}\text { Versus } \\
\text { standard p- } \\
\text { value }\end{array}$ & Mean (SD) & $\begin{array}{c}\text { Versus } \\
\text { standard p- } \\
\text { value }\end{array}$ & Mean (SD) & $\begin{array}{c}\text { Versus } \\
\text { standard p- } \\
\text { value }\end{array}$ \\
\hline Low $(n=91)$ & $2.4(1.4)$ & $2.8(1.7)$ & 0.001 & $2.7(1.6)$ & $<0.001$ & $2.4(1.5)$ & 0.39 & $2.4(1.4)$ & 0.26 \\
\hline $\begin{array}{l}\text { Borderline } \\
(\mathrm{n}=3 \mathrm{l})\end{array}$ & $6.0(0.7)$ & $6.5(1.6)$ & 0.04 & $6.6(1.0)$ & $<0.001$ & $5.9(1.4)$ & 0.82 & $6.1(0.9)$ & 0.33 \\
\hline $\begin{array}{l}\text { Intermediate } \\
(\mathrm{n}=42)\end{array}$ & $12.0(3.1)$ & $13.5(4.9)$ & 0.006 & $13.0(3.8)$ & 0.001 & $12.4(4.1)$ & 0.25 & $12.0(3.1)$ & na. \\
\hline High $(n=7)$ & $27.4(3.7)$ & $27.7(7.2)$ & 0.13 & $30.5(5.7)$ & 0.04 & $25.1(6.4)$ & 0.19 & $27.4(3.7)$ & n.a. \\
\hline $\begin{array}{l}\text { Total Subjects } \\
(\mathrm{n}=171)\end{array}$ & $6.4(6.2)$ & $7.1(6.9)$ & $<0.001$ & $7.1(6.9)$ & $<0.001$ & $6.4(6.2)$ & 0.85 & $6.4(6.2)$ & 0.56 \\
\hline
\end{tabular}

Note:

Correlation coefficient $(r)$ between ASCVD from standard (clinic) and home measurement: $r=0.950$, $p$ value $<0.001$.

$\mathrm{SBP}=$ Systolic Blood Pressure; $\mathrm{TC}=$ total cholesterol; $\mathrm{FBG}=$ fasting blood glucose; low, borderline, intermediate, and high risk $=<5 \% ; 5 \%-<7.5 \% ; 7.5 \%-<20 \% ; \geq 20 \%$ ASCVD 10-year risk score;

n.a. = not applicable; the t-test cannot be computed because the standard error of the difference is zero.

\section{CONCLUSION}

The ASCVD risk scores calculated using the PCE method obtained from clinic-measured and home-measured blood pressure, total cholesterol, and fasting blood sugar were significantly different at 6.4 (6.2) versus 7.1 (6.9) with $p$-value $=0.001$, but similarly categorized at borderline risk.

\section{ACKNOWLEDGMENTS}

Researchers would like to express gratitude to all subjects and chief of villagers in the study sites for their kind support during the research. The funding of this study was supported by Lembaga Penelitian dan Pengabdian Masyarakat Sanata Dharma University

\section{REFERENCES}

American Diagnostic Corporation. (2008). Accurate blood pressure measurement: why do monitors read high? (pp. 1-2). Commerce Drive, Hauppauge.

Blaurock, M. G., Kallner, A., Menzel, S., Masuch, A., Nauck, M., \& Petersmann, A. (2018). Impact of glucose measuring systems and sample type on diagnosis rates of diabetes mellitus. Diabetes Therapy, 9(5), 2029-2041. https://doi.org/10.1007/s13300-018-0495-0

Boyd, R., Leigh, B., \& Stuart, P. (2005). Capillary versus venous bedside blood glucose estimations. Emergency Medicine Journal, 22(3), 177-179. https://doi.org/10.1136/emj.2003.011619

Chan, Y. H. (2005). Biostatistics 304. Cluster analysis. Singapore Medical Journal, 46(4), 153-160.

Davis, B. H., McLaren, C. E., Carcio, A. J., Wong, L., Hedley, B. D., Keeney, M., Curtis, A., \& Culp, N. B. (2013). Determination of optimal replicate number for validation of imprecision using fluorescence cell-based assays: Proposed practical method. Cytometry Part B - Clinical Cytometry, 84(5), 329-337. https://doi.org/10.1002/cyto.b.21116

Douglas, G., \& Channon, K. M. (2014). The pathogenesis of atherosclerosis. Medicine (United Kingdom), 42(9), 480-484. https://doi.org/10.1016/j.mpmed.2014.06.011

Dupont, W. D., \& Plummer, W. D. (1998). Power and sample size calculations for studies involving linear regression. Controlled Clinical Trials, 19(6), 589-601. https://doi.org/10.1016/S01972456(98)00037-3

Gisev, N., Bell, J. S., \& Chen, T. F. (2013). Interrater agreement and interrater reliability: Key 
concepts, approaches, and applications. Research in Social and Administrative Pharmacy, 9(3), 330-338. https://doi.org/10.1016/j.sapharm.2012.04.004

Greenland, P., Bowley, N. L., Meiklejohn, B., Doane, K. L., \& Sparks, C. E. (1990). Blood cholesterol concentration: Fingerstick plasma vs venous serum sampling. Clinical Chemistry, 36(4), 628630.https:/doi.org/10.1093/clinchem/36.4.628

Grundy, S. M., Stone, N. J., Bailey, A. L., Beam, C., Birtcher, K. K., Blumenthal, R. S., Braun, L. T., de Ferranti, S., Faiella-Tommasino, J., Forman, D. E., Goldberg, R., Heidenreich, P. A., Hlatky, M. A., Jones, D. W., Lloyd-Jones, D., Lopez-Pajares, N., Ndumele, C. E., Orringer, C. E.,

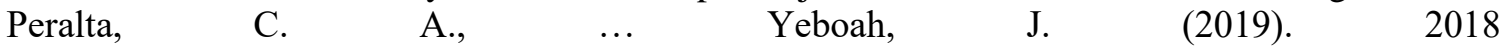
AHA/ACC/AACVPR/AAPA/ABC/ACPM/ADA/AGS/APhA/ASPC/NLA/PCNA Guideline on the Management of Blood Cholesterol: Executive Summary: A Report of the American College of Cardiology/American Heart Association Task Force on Clinical Practice Guidelines. Journal of the American College of Cardiology, 73(24), 3168-3209. https://doi.org/10.1016/j.jacc.2018.11.002

Kwak, S. G., \& Kim, J. H. (2017). Cornerstone of modern statistics. Korean Journal of Anesthesiology, 70(2), 144-156

Lloyd-Jones, D. M., Braun, L. T., Ndumele, C. E., Smith, S. C., Sperling, L. S., Virani, S. S., \& Blumenthal, R. S. (2019). Use of risk assessment tools to guide decision-making in the primary prevention of atherosclerotic cardiovascular disease: a special peport from the american heart association and american college of cardiology. Journal of the American College of Cardiology, 73(24), 3153-3167. https://doi.org/10.1016/j.jacc.2018.11.005

Midilli, T. S., Ergın, E., Baysal, E., \& Arı, Z. (2019). Comparison of glucose values of blood samples taken in three different ways. Clinical Nursing Research, 28(4), 436-455. https://doi.org/10.1177/1054773817719379

Myers, M. G., McInnis, N. H., Fodor, G. J., \& Leenen, F. H. H. (2008). Comparison between an automated and manual sphygmomanometer in a population survey. American Journal of Hypertension, 21(3), 280-283. https://doi.org/10.1038/ajh.2007.54

Nargesi, A. A., Ghazizadeh, Z., Larry, M., Morteza, A., Heidari, F., Asgarani, F., Esteghamati, A., Mohammad, K., \& Nakhjavani, M. (2014). Manual or automated sphygmomanometer? A historical cohort to quantify measurement bias in blood pressure recording. Journal of Clinical Hypertension, 16(10), 716-721. https://doi.org/10.1111/jch.12400

Parikh, P., Mochari, H., \& Mosca, L. (2009). Measurement issues: clinical utility of a fingerstick technology to identify individuals with abnormal blood lipids and high-sensitivity C-reactive protein levels. American Journal of Health Promotion, 23(4), 279-282. https://doi.org/10.4278/ajhp.071221140

Pariona, A. (2017). Leading causes of death in Indonesia - WorldAtlas. https://www.worldatlas.com/articles/leading-causes-of-death-in-indonesia.html

Patel, N., \& Patel, K. (2015). A comparative study of venous and capillary blood glucose levels by different methods. GCSMC J Med Sci, IV(June), 53-56.

Pickering, T. G., Hall, J. E., Appel, L. J., Falkner, B. E., Graves, J., Hill, M. N., Jones, D. W., Kurtz, T., Sheps, S. G., \& Roccella, E. J. (2005). Recommendations for blood pressure measurement in humans and experimental animals: Part 1: Blood pressure measurement in humans - A statement for professionals from the Subcommittee of Professional and Public Education of the American Heart Association Co. Circulation, 697-716. https://doi.org/10.1161/01.CIR.0000154900.76284.F6

Rajaratnam, H., \& Pathmanathan, S. (2012). How reliable are capillary blood glucose measurements? Sri Lanka Journal of Diabetes Endocrinology and Metabolism, 1(1), 23-24. https://doi.org/10.4038/sjdem.v1i1.4184

Riddle, M. C., Bakris, G., Boulton, A. J. ., D’Alessio, D., De Groot, M., Greene, E. L., \& Hu, F. B. 
(2018). Updates to the Standards of Medical Care in Diabetes-2018. Diabetes Care, 41(9), 20452047. https://doi.org/10.2337/dc18-su09

Roth, G. A., Johnson, C., Abajobir, A., Abd-Allah, F., Abera, S. F., Abyu, G., Ahmed, M., Aksut, B., Alam, T., Alam, K., Alla, F., Alvis-Guzman, N., Amrock, S., Ansari, H., Ärnlöv, J., Asayesh, H., Atey, T. M., Avila-Burgos, L., Awasthi, A., ... Murray, C. (2017). Global, regional, and national burden of cardiovascular diseases for 10 causes, 1990 to 2015. Journal of the American College of Cardiology, 70(1), 1-25. https://doi.org/10.1016/j.jacc.2017.04.052

Sblendorio, V., Palmieri, B., \& Riccionii, G. (2008). Fingerstick versus venous sampling. International Journal of Immunopathology and Pharmacology, 21(3), 729-733

Stergiou, G. S., Asayama, K., Thijs, L., Kollias, A., Niiranen, T. J., Hozawa, A., Boggia, J., Johansson, J. K., Ohkubo, T., Tsuji, I., Jula, A. M., Imai, Y., \& Staessen, J. A. (2014). Prognosis of whitecoat and masked hypertension: International database of home blood pressure in relation to cardiovascular outcome. Hypertension, 63(4), 675-682. https://doi.org/10.1161/HYPERTENSIONAHA.113.02741

Stone, N. J., Robinson, J. G., Lichtenstein, A. H., Bairey, C. N., Blum, C. B., Eckel, R. H., Goldberg, A. C., Gordon, D., Levy, D., Lloyd-Jones, D. M., McBride, P., Schartz, J. S., Shero, S. T., Smith, S. C., Watson, K., \& Wilson, P. W. . (2015). Erratum: 2013 ACC/AHA guideline on the treatment of blood cholesterol to reduce atherosclerotic cardiovascular risk in adults: A report of the American college of cardiology/American Heart association task force on practice guidelines. Journal of the American College of Cardiology, 66(24), 2812. https://doi.org/10.1016/j.jacc.2015.11.019

Suhadi, R., Linawati, Y., Wulandari, E. T., Viriginia, D. M., \& Setiawan, C. H. (2017). The metabolic disorders and cardiovascular risk among lower socioeconomic subjects in Yogyakarta-Indonesia. Asian Journal of Pharmaceutical and Clinical Research, 10(3), 367-372. https://doi.org/10.22159/ajpcr.2017.v10i3.16310

Unger, T., Borghi, C., Charchar, F., Khan, N. A., Poulter, N. R., Prabhakaran, D., Ramirez, A., Schlaich, M., Stergiou, G. S., Tomaszewski, M., Wainford, R. D., Williams, B., \& Schutte, A. E. (2020). 2020 international society of hypertension global hypertension practice guidelines. Hypertension, 75(6), 1334-1357. https://doi.org/10.1161/HYPERTENSIONAHA.120.15026 
